\title{
BEHAVIOUR OF JOINTS IN SANDSTONES DURING THE SHEAR TEST
}

\author{
Piotr MAŁKOWSKI
}

AGH University of Science and Technology, al. Mickiewicza 30, 30-059 Krakow, Poland

*Corresponding author's e-mail: malkgeom@agh.edu.pl

\begin{tabular}{l} 
ARTICLE INFO \\
\hline Article history: \\
Received 9 March 2015 \\
Accepted 29 June 2015 \\
Available online 10 August 2015 \\
\hline
\end{tabular}

Keywords:

Shear strength,

Shear stiffness,

Joint roughness coefficient,

Laboratory research on sandstones

\begin{abstract}
In the case of soft rocks, with many beds, or subjected to tectonic tensions, fractures with the separation occur, which cause many problems to the quantitative assessment of their properties. Considering the fact that deformation properties are proportionate to the strength properties also in the case of rocks, measurement of shear stresses can become the basis for quantitative assessment of mechanical properties of rocks joints, in particular as regards their shear stiffness. In the article, the author has presented the results of laboratory studies of shear behaviour of rock joints in Carboniferous sandstones: fine- and medium grained during a shear test. He has presented the values of internal friction angle, cohesion, shear stiffness at the rock joints, as well as joint roughness coefficient. All the tests were carried out at low stresses with the help of direct shear test.

The results show that the internal friction angle of fractured sandstones and of intact ones tested at low stress (up to $10 \mathrm{MPa}$ ) is similar. Shear stiffness $K_{s}$ of joints grows up with the normal stress and correspond with the shifting on the discontinuity. For the low normal stresses $K_{s}$ was obtained as follows: $320 \mathrm{MPa} / \mathrm{m}, 353 \mathrm{MPa} / \mathrm{m}$ and $418 \mathrm{MPa} / \mathrm{m}$. The joint roughness coefficient (JRC) for the fine-grained sandstone amounts to 5 to 7 , while for medium-grained sandstone - 6 to 8. This conclusion can be very useful for geological or engineering designing (eg. mining workings support design, underground roadways stability assessment, rock mass classification) when evaluate the shear resistance between sandstone rock blocks.
\end{abstract}

\section{INTRODUCTION}

The role of fractures in the assessment of rock properties is testified to by a high number of publications on this subject, principally by Barton's team (Barton, 1972, 1973, 1976, 1995; Barton and Choubey, 1977; Barton and Bandis, 1990). The biggest problem is to make a quantitative assessment of the mechanical rock properties if they are jointed. Diederichs and Kaiser (1999) even stated that the shear strength of the rocks and the parameters of their joints, can be used to control the stability of underground headings. An increase in the number of fractures leads to increasing displacements inside the rock mass, and the nature of this increase is close to the exponential curve (Arunakumari and Madhavi Latha, 2007). It must be considered that while modelling rock as a fractured medium, its mechanical parameters are reduced. While performing tests on cement-bentonite samples with the size $100 \times 100 \times 100 \mathrm{~mm}$ with randomly oriented joints created by the insertion of thin papers, Yamachi et al. (1989) stated that with the increase in the number of joints, the strength and deformability of brittle materials are reduced respectively by approx. $17 \%$, $46 \%$, and $68 \%$ with the number of 10,30 , and 50 joints, respectively. Srivedi and Sitharam (2000), in turn, point out that in the case a of high joint ratio (greater than 400), characterising not only the number of joints, but also their slanting and roughness, Young's modulus for the rock is reduced to practically zero.

In the case of analysing the very joint alone, it can be stated that the strength and stiffness at the contact points differ from those of intact rock. The parameters are determined and defined in a different manner. Therefore some researchers use an intangible parameters as for example the effective friction coefficient without dilatancy between jointed surfaces (Gerrard, 1986).

In this article, the author has presented the results of laboratory studies of the shear behaviour of rock joints in carboniferous sandstones. He has also presented the values of normal and shear stiffness of rock joints, as well as joint roughness coefficient.

\section{NORMAL AND SHEAR STIFFNESS OF JOINTS, SHEAR STRENGTH OF JOINTS}

Joint parameters of the fractures are affected by various factors, such as granularity of the rock, mutual pressure force, joint opening, angle of joint, moisture, filling with another material, and other (Barton, 1973, 1976, 1995; Barton and Choubey, 1977; Gerrard, 1986; Goodman, 1989; Hoek et al., 1995; Grasselli, 2001; Brady and Brown, 2004). Consideration of all of them therefore is practically impossible, however, it can be stated that the fundamental parameters 
describing the mechanical properties of a fracture, and this relation to the material generated at its joint, due to the friction caused by the adjacent rock layer are: shear stiffness $K_{s}$ and normal stiffness $K_{n}$, expressed in $\mathrm{MPa} / \mathrm{m}$. The first time this was quantitatively described by Barton (1972), stating that:

$$
\begin{aligned}
& K_{n}=-\frac{E_{i} \cdot E_{m}}{L\left(E_{i}-E_{m}\right)} \\
& K_{s}=-\frac{G_{i} \cdot G_{m}}{L\left(G_{i}-G_{m}\right)},
\end{aligned}
$$

where $E-$ is the Young's modulus, $G$ - shear modulus, while indices $i$ and $m$ refer to intact rock and rock mass, respectively. $L$ means the average interval of joints.

When performing a quantitative analysis of the formula above, using the relation between the modules known from material strength and resulting from pure shearing of the material in state of stress with two dimensions:

$$
G=\frac{E}{2(1+v)},
$$

it can be noticed that while adopting the same Poisson ratio $v$ for the sample and rock mass, the proportion of both stiffness types $K_{n} / K_{s}$ is brought down to $2(1+v)$. It can then adopt values from 2 to 3 , because Poisson ratio can have value from 0 to 0.5 . When assuming that the Poisson ratio for a sample (intact rock) and a rock mass differs $v_{i} \neq v_{m}$, one can find the following proportion:

$$
\frac{K_{n}}{K_{s}}=-\frac{2 E_{i}\left(1+v_{m}\right)-2 E_{m}\left(1+v_{i}\right)}{E_{i}-E_{m}}
$$

At this point, solving the equation (4) for $E_{i}=2 E_{m}$ the normal stiffness $K_{n}$ of the joint will be greater than shear stiffness $K_{s}$ by 1 to 4 times, solving it for $E_{i}=4 E_{m}$ the joint stiffness proportion will be 5 to 10 .

In practice both stiffness types are to determine the Young's modulus $E_{o}$ and shear modulus $G_{o}$ of the material filling the joint with a thickness of $h$, according to the simplest correlations (Phase2 Tutorials), these can be defined as:

$$
\begin{aligned}
& K_{n}=-\frac{E_{o}}{h} \\
& K_{s}=-\frac{G_{o}}{h}
\end{aligned}
$$

Because both stiffness types are generally used during the numerical modelling of the joints, and joint filling is often minimal, amounting to millimetres or fractions of a millimetre, software such as UDEC or Phase by default provide stiffness values as $K_{n}=10^{5} \mathrm{MPa} / \mathrm{m}$, and $K_{s}=10^{4} \mathrm{MPa} / \mathrm{m}$. Assuming clay joint filling with the $\mathrm{E}=200 \mathrm{kPa}$ these values often seem to be too high, however are still frequently blindly applied. Moreover the $K_{n} / K_{s}$ ratio is rather unknown. Brady and Brown (2004) assume up to 50 times difference between both stiffnesses, stating that the data for quantitative assessment of stiffness cannot be determined, and the degree of rock fracturing is more random than had been assumed in previous analytical studies. All authors studying the above issue (Barton, 1973, 1976; Goodman, 1989; Haque, 1999; Brady and Brown, 2004; Hoek, 2013) generally agree on these qualitative descriptions and as a result provide equal numerical values (Gerrard, 1986). Such conclusions confirm the fact that the assumed proportion between both stiffness types is usually purely estimated. Some authors thus attempt to modify constitutive in-built equations in calculation software, assuming the own author's equations for reactions at the joints' surfaces (Arunakumari and Madhavi Latha, 2007).

Slightly different approach to the issue has been presented by FLAC software (Flac, 7.0 Manuals), where it is suggested that in order to limit deformation at joints, shear and normal stiffness should be determined as the lowest stiffness sets to ten times the equivalent stiffness of the stiffest neighbouring zone, as:

$K_{n}=K_{s}=\max \left[\frac{K+\frac{4}{3} G}{\Delta z_{\min }}\right]$

where $K$ and $G$ are, respectively, bulk and shear moduli at the joints, while $\Delta z$ - the width of the smallest element of the generated calculation grid in contact with the joint (Flac, 7.0 Manuals). In this case, both stiffness types are equal.

Yet another definition of stiffness was adopted by Rechitskii (1998). According to him, stiffness is the proportion between the stress and the resulting shift at the joint. The author differentiates between three shear stiffness types: $K_{s i}$ referred to as initial stiffness, determined on the basis of the initial point of quasi-linear characteristics $\tau-u$; average stiffness $K_{s 50}$, which describes the proportion $\tau-u$ for $50 \%$ of final shear strength and stiffness $K_{\text {slim }}$ adopted for full-slip, namely the ratio of the value of shear strength leading to shear (the one prevailing for some time) and the shift caused at the time $u_{\text {lim }}$. Such an approach to the issue causes the above stiffness types to differ by even an order of $10^{2} \mathrm{~Pa} / \mathrm{m}$. According to Rechitskii, depending on height $h$ and width $m$ of the joint, stiffness $K_{s 50}$ is on average 6-times higher than stiffness $K_{\text {slim }}$, considering the following empirical formulas (Rechitskii, 1998): 


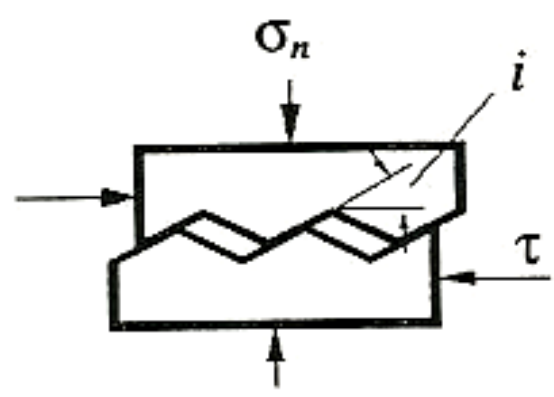

Fig. 1 Asperity angle during shearing (Barton, 1976).

$$
\begin{gathered}
K_{\text {slim }}=\frac{4 \sigma^{\frac{2}{3}}}{1+5\left(\frac{m}{h}\right)^{2}} \\
K_{s 50}=\frac{24 \sigma^{\frac{2}{3}}}{1+5\left(\frac{m}{h}\right)^{2}}
\end{gathered}
$$

In order to solve this quantitative problem with regard to the correct adoption of stiffness at the fracture joint, one can use Barton's conclusions (1973, 1976), which state that the shear condition at joints is a modified Coulomb condition (6) or (7), in line with deliberations by Patton, as well as Newland and Allely (Barton, 1976; Goodman, 1989):

$$
\begin{aligned}
& \tau=\sigma_{n} \tan \left(\varphi_{b}+i\right) \\
& \tau=\sigma_{n} \tan \varphi_{r}+c
\end{aligned}
$$

where $\phi_{b}$ is the angle of friction between the joint surfaces shifting across one another, $i$ is the asperity angle (see Figure 1) - deflection of friction surface forced by the displacement, resulting from the uneven surface, $\phi_{r}$ is the residual angle of friction of joint surfaces moving across one another in a slip, while $c$ is the cohesion at joint contact point.

According to Figure 2 (Goodman, 1989; Hoek et al., 1995; Brady and Brown, 2004), it can be stated that in the case of large roughness, thus also small stresses, it is more appropriate to apply equation (10), whereas in the case of a joint surface smoothed by friction - equation (11) should be applied. Nevertheless, Goodman points out that many studies indicate that both angles $\phi_{b}$ and $\phi_{r}$ have very similar values, and the additional angle $i$ can often be neglected, as it results from the height of unevenness teeth on the joint surface.

Barton and Bandis (1990) stress that strength at the joint contact points depends on the way of asperity failure, geometry of the discontinuity and residual or basic friction between the joint surfaces.

On the basis of laboratory studies performed together with Choubey (Barton and Choubey, 1977), Barton finally stated that maximum shear strength on

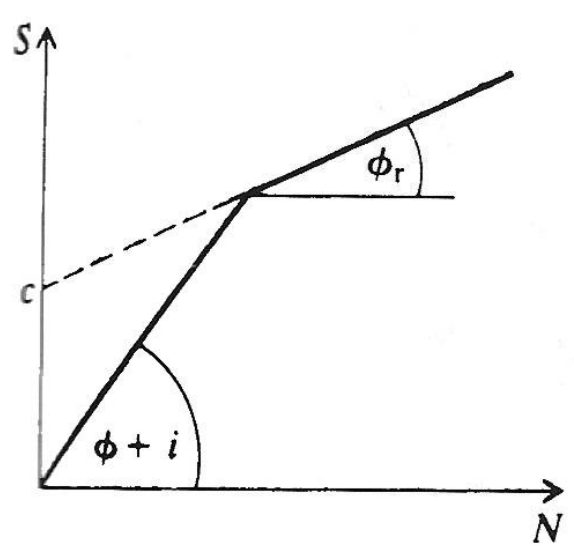

Fig. 2 Bilinear joint shear criterion (Goodman, 1989).

the joint surface also depends on the Joint Wall Compressive Strength (JCS) and Joint Roughness Coefficient (JRC), according to the following formula:

$$
\left.\tau=\sigma_{n} \tan \left(J R C \log _{10}\left(\frac{J C S}{\sigma_{n}}\right)+\varphi_{b}\right)\right)
$$

In this case, $\phi_{b}$ was obtained during shear test of unweathered surfaces of fractured rock. It's worth underlining that the factor that can significantly affect mechanical parameters of the joints is the presence of water and filling of the joints with sedimentary material (Barton, 1973, 1976; Gerrard, 1986; Hoek et. al., 1995; Haque, 1999; Hoek, 2013).

Based on their conclusions, Barton and Chubey (1977), by dividing the shear stress determined formula (12) and also suggested the possibility of determining shear stiffness $k_{s}$ :

$\left.k_{s}=\frac{100}{L_{x}} \sigma_{n} \tan \left(J R C \log _{10}\left(\frac{J C S}{\sigma_{n}}\right)+\varphi_{r}\right)\right)$

In the above formula, $L_{x}$ is the distance between the joints in metres.

However any formula which expressed the shear strength or stiffness can be useful if it is based on parameters easily measured under both laboratory and in-situ conditions (Grasselli, 2001). Considering this fact, deformation properties are also proportionate to strength properties in the case of rocks (Bukowska, 2005). Measurement of shear stresses can therefore become the basis for the quantitative assessment of the mechanical properties of rocks in joints with particular regard to their stiffness.

\section{SHEAR OF CRACKED SANDSTONES}

In order to perform a quantitative assessment of friction resistance of joints, the author carried out special laboratory studies on fine-grained and medium-grained sandstone. The maximum size for fine-grained sandstones didn't exceed $0.5 \mathrm{~mm}$ and for 


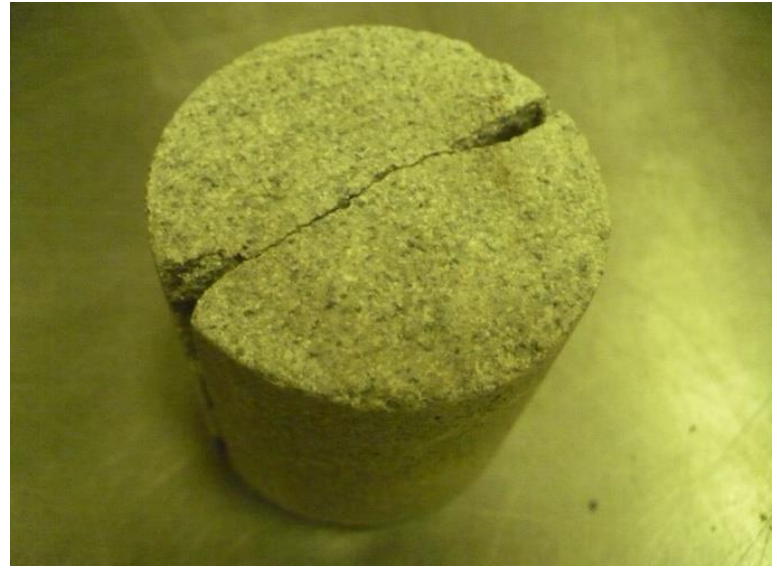

Fig. 3 Sample of fine-grained sandstone destroyed during Brazilian tensile strength test.

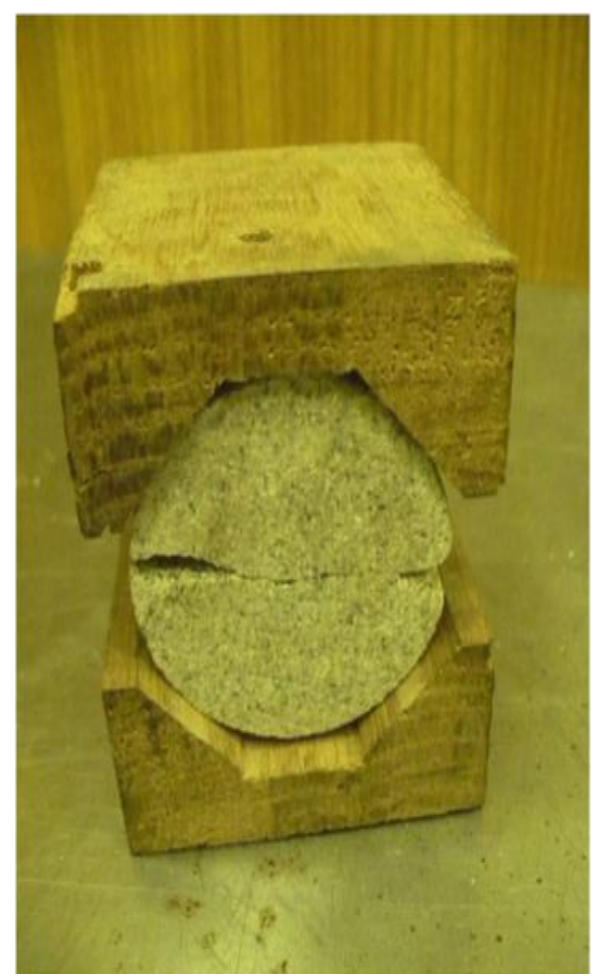

Fig. 5 Sample of sandstone placed in wooden forms.

medium-grained sandstones was from $0.5 \mathrm{~mm}$ up to $2.5 \mathrm{~mm}$. The methodology was based on a direct shear test in box apparatus, the method recommended for such analyses (Goodman, 1989; Brady and Brown, 2004). The study involved 14 cylindrical samples taken from the southern region of Upper Silesia, previously failed during Brazilian tensile strength test, during which they were divided into two halves (Figs. 3 and 4). The samples featured were about $50 \mathrm{~mm}$ long with the diameter of $50 \mathrm{~mm}$. The samples then were placed in prepared wooden forms (Fig. 5) and then to the direct shear apparatus box (Fig. 6), so that the surface of the crack (after Brazilian test) should be parallel to the shear load and perpendicular to the normal load. After loading the sample with axial strength, the shifting of the two pieces of rock

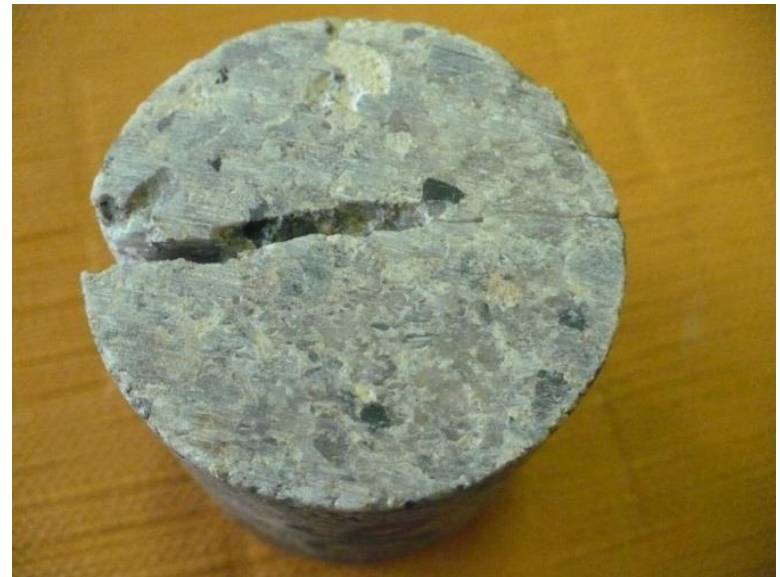

Fig. 4 Sample of thick-grained sandstone destroyed during Brazilian tensile strength test.

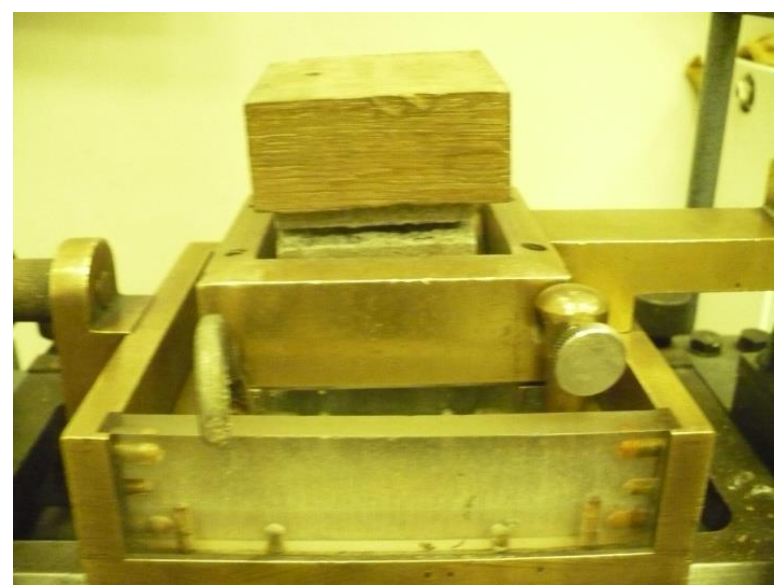

Fig. 6 Sample of sandstone placed in the box apparatus in a crack parallel to shear load.

using increasing shear load was applied, to a displacement equal to $10 \mathrm{~mm}$. The tests were carried out five times for each specimen at three normal stresses in the range of $0.19-0.35 \mathrm{MPa}, 0.42-0.70 \mathrm{MPa}$ and 0.65-1.08 MPa; in total, 200 measurements were thus performed (two specimens were only tested for two normal stresses). The shear tests done at the same range of normal stress were named consequently: the first, second and third shear series. The change in stress applied resulted from a change in the sample surface area, because during the rock's damage, by applying tensile strength the rocks partially crush, hence the area of the adjacent surfaces differs. Five tests were performed for the same specimen at the same normal stress to determine whether after each surface friction the friction ratio changes, resulting in a change of the internal friction angle. After each shifting both parts of the sample were then placed in the previous (original) position for further testing (Małkowski, 2013).

The tests indicate that shear resistance and the displacement occurring correlates with linear Coulomb function and is described well in the following literature (Goodman, 1989; Haque, 1999; Brady and Brown, 2004; Hoek, 2013). Haque showed 


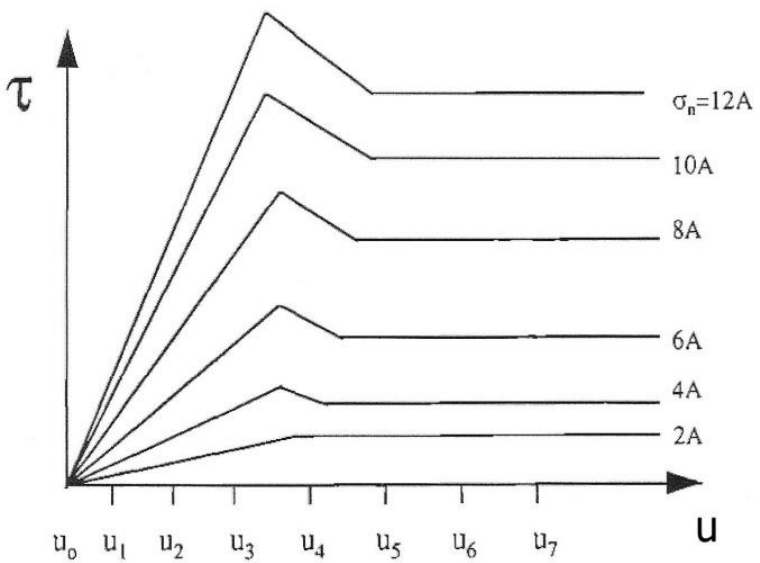

Fig. 7 Correlation between shear stress and shift with growing normal stress, A - arbitrary value of normal stress (Haque, 1999).

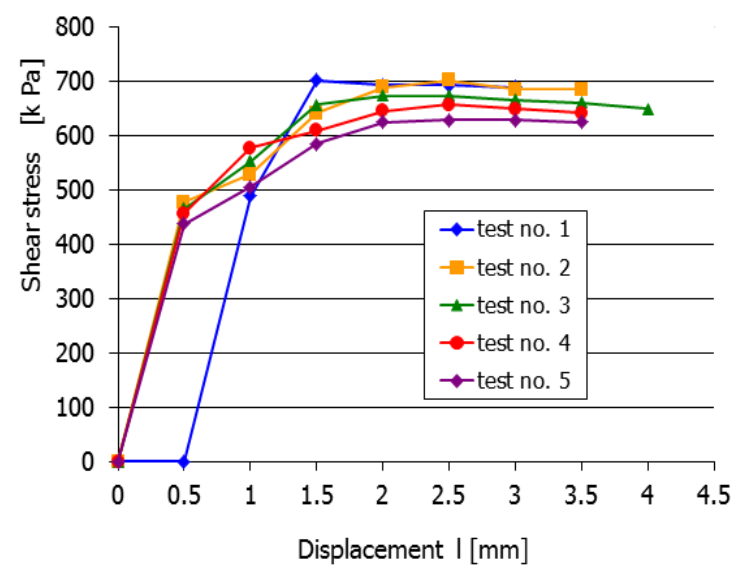

Fig. 9 Correlation of shear stress and the displacement for sample No. 16, at normal stress of $571 \mathrm{kPa}$.

that the course of the Coulomb-Mohr line is strictly depended on the value of normal stress (Fig. 7). According to theory, the shear stress should increase with the arbitrary value of normal stress $\sigma$ and when the shear displacement reaches its maximum and then decreases slightly. In the case of the fractured sandstone specimens, a continuous increase in shear stress occurred for consecutive applied normal stresses (Fig. 8). However, the specimens behaved in two manners: either displacement along the fracture occurred in a very similar way in all five tests, whereas a slight decrease in stress was observed (Fig. 9), or for the first (possibly the second) measurement, both parts of the rock clinched and the value of shear stress causing a slip on the crack surface was much higher, sometimes almost doubled the other values (Fig. 10). In the latter case, there was a clear peak of shear resistance.

Such behaviour is typical of high roughness of surfaces and very thin (or zero) layer of material

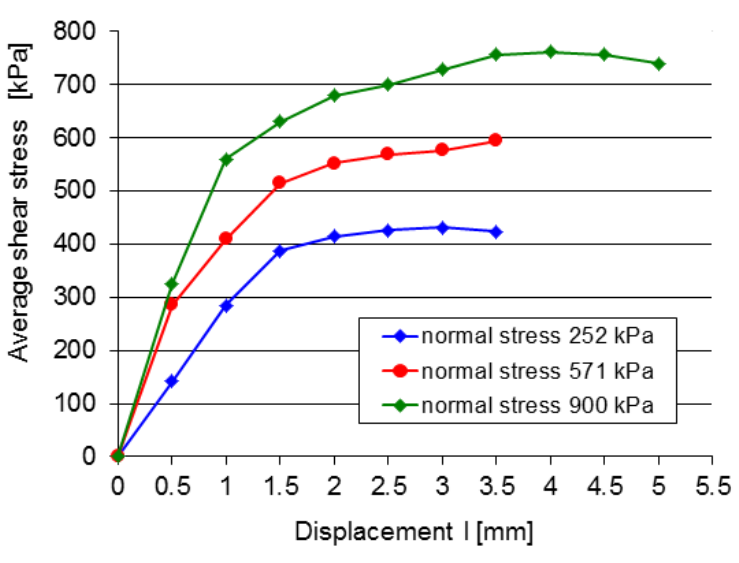

Fig. 8 Correlation between average shear stress and the displacement with growing normal stress for sample No. 118 .

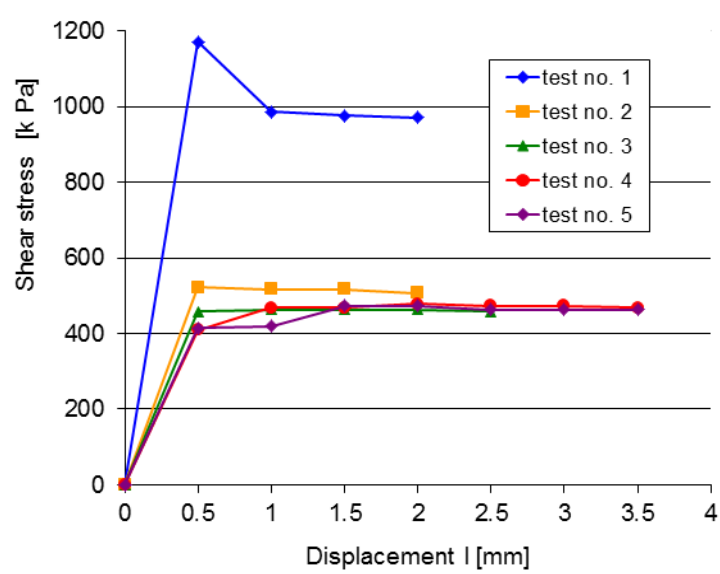

Fig. 10 Correlation of shear stress and the displacement for sample No. 122, at normal stress of $252 \mathrm{kPa}$.

filling the joint (Haque, 1999) and typical for bilinear joint shear behaviour (Goodman, 1989).

The ratio of shear stress to normal stress $\tau / \sigma$ decreased with increasing load in another series of tests, but this depended on the grain size in the rock. It was observed that higher shear stress values were recorded for sandstones with a greater grain size, namely medium-grained sandstones. On average, in all tests for sandstones the proportion amounted to: 1.31, 1.16 and 1.04 (Fig. 11), whereas for fine-grained sandstones this was: $1.18,1.07$ and 0.95 , while for medium-grained sandstones: $1.41,1.22$ and 1.09 (Małkowski, 2013). Therefore, a slow reduction of approx. $10 \%$ occurred in the stress proportion with each increase in normal stress, related to gradual friction of adjacent surfaces (Fig. 12). This was principally noticeable in fine-grained sandstones.

The analysed proportions differ in the case of rock clinching in the joint (Fig. 13), which - if it occurred - usually took place in the first shear test. In 


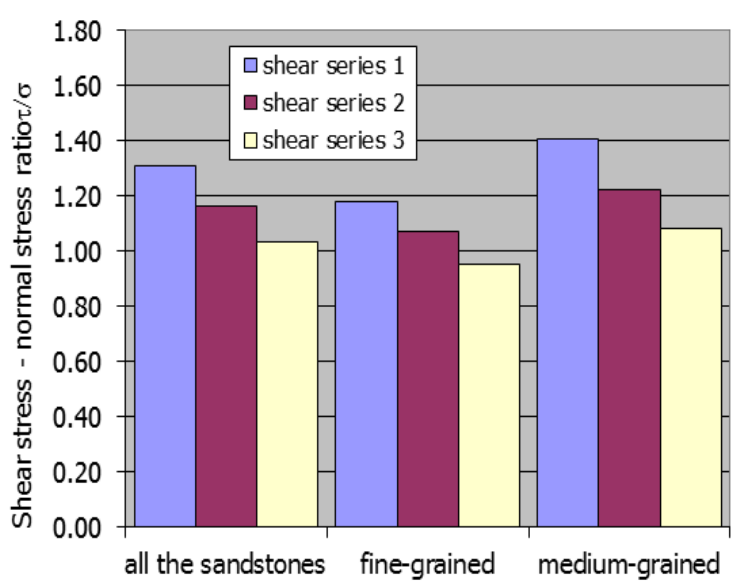

Fig. 11 Average proportion between shear and normal stress during consecutive three shear series for all symplex.

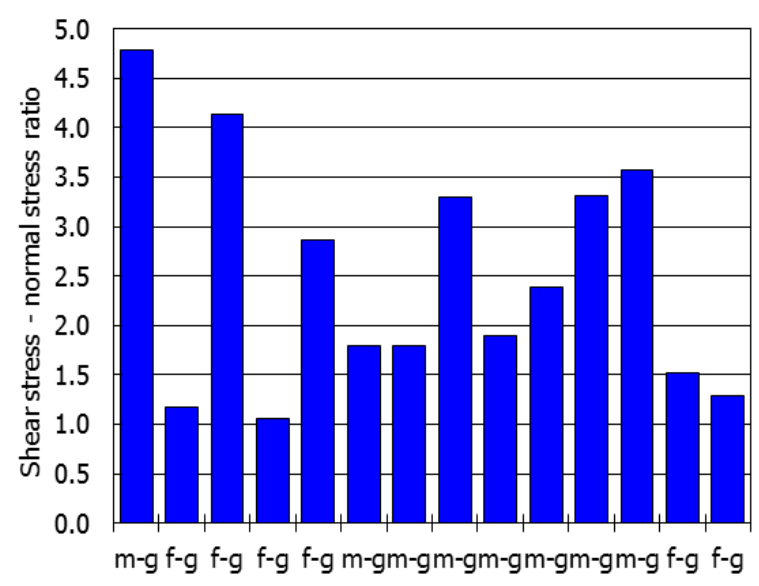

Fig. 13 Shear to normal stress ratio during the first shear test (f-g fine-grained sandstone, $\mathrm{m}-\mathrm{g}-$ medium-grained sandstone).

such a case, the $\tau / \sigma$ ratio could increase by up to 4.79 . More frequently and more intensively, a shift blockage occurred in the joint of medium-grained than fine-grained sandstones (Fig. 14), hence for sandstones with larger grains $\tau_{\max } / \sigma$ which on average amounted to 2.67, and for finer-grained sandstones 1.26. The average proportions between shear and normal stress during the first shear series without blocking for particular samples ranged from 1.06 to 1.90 (Fig. 14).

Summing up, the ratio shear stress - normal stress is greater than one and slightly decreases below one after several shifts and friction of fractured rock layers. Total shear stresses are higher than normal stresses, which is caused by the slight cohesion of material filling the joint.

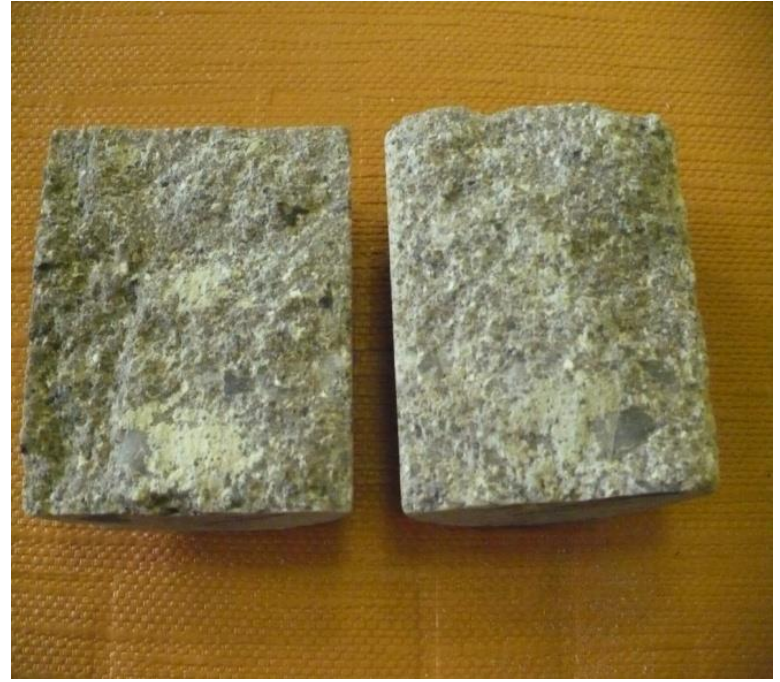

Fig. 12 Primary crack surface of fine-grained sandstone after 15 shear tests.

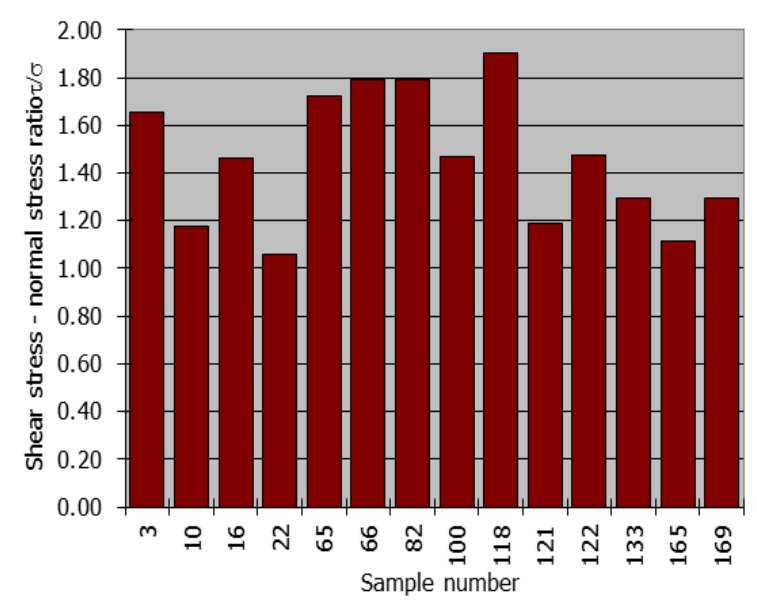

Fig. 14 Proportion between shear and normal stress for the first shear series for consecutive samples.

\section{ASSESSMENT OF FRICTION ANGLE AND JOINT ROUGHNESS}

For the 14 tests performed, the average internal friction angle of the joints of fractured sandstones equalled $41.45^{\circ}$ and cohesion was $120 \mathrm{kPa}$. For finegrained sandstone, it amounted to $37.0-44.1^{0}$, while for medium-grained sandstone $-32.9-49.2^{0}$, whereas cohesion changed within the range of from 50 to $125 \mathrm{kPa}$ for fine-grained sandstone, from 47 to $268 \mathrm{kPa}$ for medium-grained sandstone (Figs. 15 and 16). The results obtained for internal friction angles are similar to the results obtained by Sanetra (2005) at the Central Mining Institute in Katowice, where the values for carboniferous sandstones (the same coalmine basin) tested at the low confining pressure of $10 \mathrm{MPa}$ within the range of $40.0-41.1^{0}$ were obtained. 


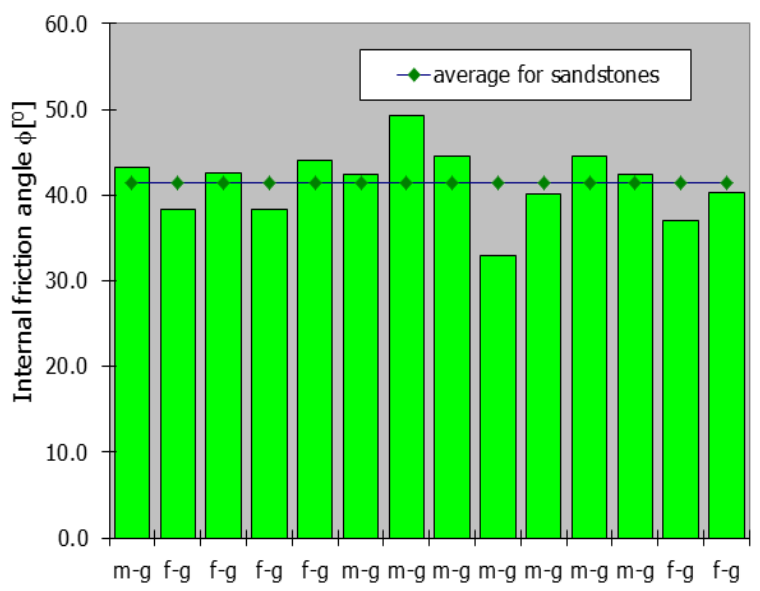

Fig. 15 Internal friction angle test results for sandstones (f-g fine-grained sandstone, $\mathrm{m}-\mathrm{g}-$ medium-grained sandstone).

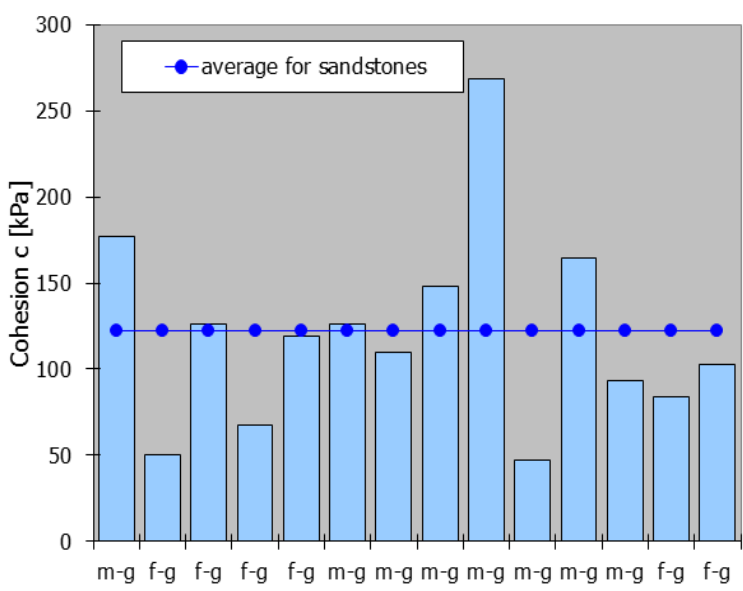

Fig. 16 Cohesion test results for sandstones (f-g finegrained sandstone, $\mathrm{m}-\mathrm{g}$ - medium-grained sandstone).

Table 1 Internal friction angle for intact and fractured sandstones - uniaxial tests.

\begin{tabular}{|c|c|c|}
\hline Authors & Fine-grained sandstones & Medium-grained sandstones \\
\hline Benmokrane \& Ballivy (1998) & $22.0-29.1^{0}$ & $17.9-34.2^{0}$ \\
\hline & $19-31^{0}$ & $15-27^{0}$ \\
\hline Sanetra (2005) & $16-28^{0}$ (fractured) & $12-24^{0}$ (fractured) \\
\hline Barton \& Choubey (1977) & \multicolumn{2}{|c|}{$26-34^{0}$ (fractured) } \\
\hline Coulson (1972), Krsmanović (1967) & $26-35^{0}$ & $32-34^{0}$ \\
\hline Grasselli (2001) & $43-51^{0}($ & the peak shear values) \\
\hline Goodman (1989) & \multicolumn{2}{|c|}{$\begin{array}{l}43-51 \text { (for the peak shear values) } \\
21-40^{0}\end{array}$} \\
\hline Małkowski (2015) & $\begin{array}{c}37.0-44.1^{0} \text { (one joint) } \\
\text { av. } 40.1^{0}\end{array}$ & $\begin{array}{c}32.9-49.2^{0} \text { (one joint) } \\
\text { av. } 42.4^{0}\end{array}$ \\
\hline
\end{tabular}

The studies on sandstones performed using triaxial compression also indicate that the internal friction angle decreases with increased confining pressure, while principally with the degree of their fracturing (Sanetra, 2005). The author states that in fine-grained sandstones applied with uniaxial force, the friction angle amounts to $19-31^{\circ}$, and cohesion to $38-71 \mathrm{kPa}$, while for medium-grained sandstones friction angle amounts to $15-27^{0}$, and cohesion to $28-61 \mathrm{kPa}$, whereas for fractured ones, the friction angle is $2-3^{0}$ lower. At high confining pressure values and high normal stresses, the friction angle is a residual angle $\phi_{r}$, whereas at low values it is rather a friction angle $\phi_{b}$. The research carried out for other sedimentary rocks (e.g. limestones) and igneous rocks (e.g. granite) confirmed that for the fractured rock structure in post-failure state internal friction angle is slightly lower than for the intact ones (Bukowska and Sanetra, 2008).

It is also important that the friction resistance in cracked sandstones tested is similar to the friction angle of intact rock. According to Coulomb-Mohr criterion, based on works by Hoek (Hoek et al. 2002), with the assumption of constant $m_{i}$ equal to 17 (one of recommended for sandstones), the angles above can be obtained for RMR $=42-100$. For $R M R=60-70$, which is a typical value for carboniferous sandstones from the regions of Upper Silesia analysed (Małkowski, 2013), the value of the average friction angle obtained amounting to $38-41^{\circ}$.

When analysing test results, it can also be observed that similar shift characteristics were also obtained by Benmokrane and Ballivy (1998) when analysing sandstone from the St-Marc quarry at small asperity angles $i$ equal to $15^{\circ}$. Therefore, by adopting the equation (10) for the sandstone analysed, it could be suggested that the friction angle of the sandstone obtained was $\phi=\phi_{b}+i$, thus $\phi_{b}=\phi-i$. Hence, for finegrained sandstones $\phi_{b}=22.0-29.1^{0}$ is obtained, while for medium-grained sandstones $-\phi_{b}=17.9-34.2^{0}$, which is almost within the range of tests for carboniferous sandstones performed by Sanetra (2005) mentioned above. 


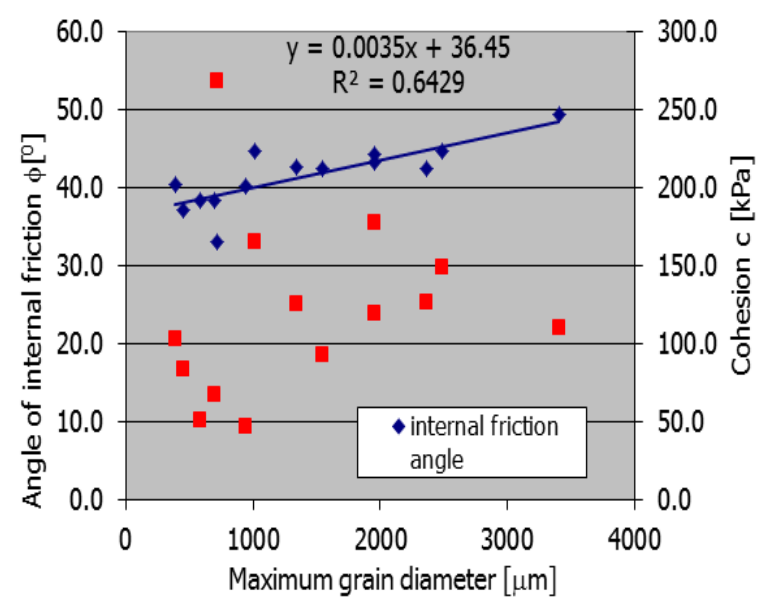

Fig. 17 Correlation between internal friction angle and cohesion of sandstones, and maximum grain size.

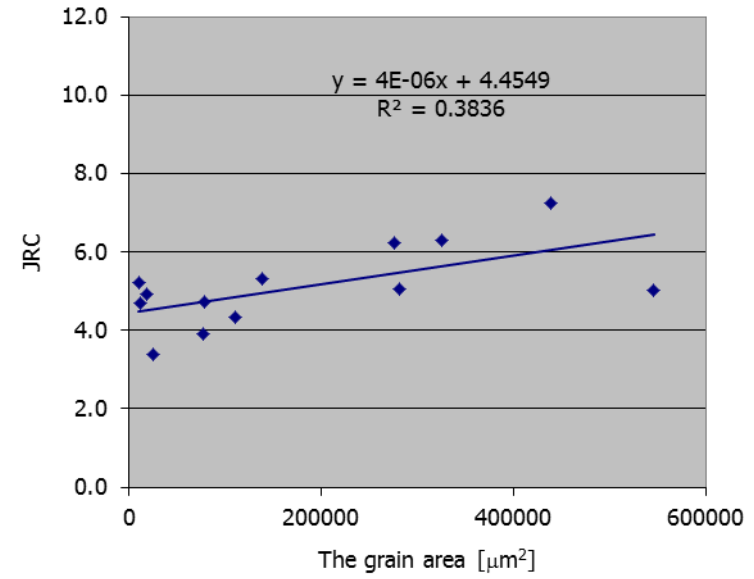

Fig. 18 Correlation of joint roughness coefficient (JRC) and grain surface area (except for sample 118).

Table 2 JRC test results in consecutive shear tests.

\begin{tabular}{ccccccccr}
\hline Sample No. & $\phi\left[^{0}\right]$ & $\mathrm{Rc}[\mathrm{MPa}]$ & $\tau_{\max 1} / \sigma_{1}$ & $\tau_{\max 2} / \sigma_{2}$ & $\tau_{\max 3} / \sigma_{3}$ & JRC- $\sigma_{\mathbf{n} 1}$ & JRC- $\sigma_{\mathbf{n} 2}$ & JRC- $\sigma_{\mathbf{n} 3}$ \\
\hline 3 & 43.27 & 78 & 1.65 & 1.51 & 1.26 & 6.30 & 7.15 & 7.83 \\
10 & 38.33 & 55 & 1.18 & 0.99 & - & 4.69 & 5.34 & - \\
16 & 42.60 & 82 & 1.46 & 1.23 & 1.12 & 5.32 & 6.04 & 6.63 \\
22 & 38.40 & 83 & 1.06 & - & 0.82 & 3.39 & - & 4.22 \\
65 & 44.12 & 65 & 1.73 & 1.47 & 1.20 & 6.24 & 7.07 & 7.73 \\
66 & 42.42 & 74 & 1.79 & 1.24 & 1.18 & 7.26 & 8.20 & 8.97 \\
82 & 49.24 & 52 & 1.79 & 1.49 & 1.34 & 5.05 & 5.78 & 6.40 \\
100 & 44.57 & 61 & 1.47 & 1.35 & 1.26 & 5.02 & 5.78 & 6.41 \\
118 & 32.95 & 111 & 1.90 & 1.40 & 1.04 & 11.08 & 12.46 & 13.56 \\
121 & 40.14 & 78 & 1.19 & 1.02 & 0.95 & 3.90 & 4.42 & 4.84 \\
122 & 44.57 & 88 & 1.47 & 1.33 & 1.26 & 4.71 & 5.37 & 5.91 \\
133 & 42.35 & 63 & 1.29 & 1.12 & 1.04 & 4.34 & 4.97 & 5.49 \\
165 & 37.09 & 48 & 1.12 & 0.98 & 0.87 & 4.93 & 5.67 & 6.29 \\
169 & 40.32 & 56 & 1.29 & 1.12 & 1.01 & 5.22 & 5.98 & 6.61 \\
sandstones & $\mathbf{4 1 . 4 5}$ & $\mathbf{7 1 . 0}$ & $\mathbf{1 . 4 6}$ & $\mathbf{1 . 2 5}$ & $\mathbf{1 . 1 0}$ & $\mathbf{5 . 8 4}$ & $\mathbf{6 . 6 6}$ & $\mathbf{7 . 3 1}$ \\
Fine-grained & 40.14 & 64.8 & 1.31 & 1.16 & 1.00 & 5.18 & 5.94 & 6.50 \\
Medium- & 42.44 & 75.6 & 1.57 & 1.31 & 1.17 & 6.22 & 7.08 & 7.78 \\
grained & & & & & & & & \\
\hline
\end{tabular}

It must also be pointed out that similar values of friction angle for fractured sandstones, amounting to 26-34 ${ }^{0}$, were recorded by Barton and Choubey (1977), however they stressed that these values were for "smooth joint surfaces", thus smoothed e.g. by high normal stress. In turn, while quoting the works by Coulson (1972) and Krsmanović (1957). Barton (1976) states that the angle range $\phi_{b}$ for dry fine-, medium and coarse-grained sandstones amounts to: $26-35^{0}, 32-34^{0}$, or $31-34^{0}$, respectively. According to Goodman (1989), the friction angle for sandstones should remain within the range of from 21 to $40^{\circ}$.
However Grasselli (2001) claimed that for the peak shear stress friction angle values can reach 43$51^{0}$. The results of mentioned laboratory tests are presented in Table 1.

The test, therefore, indicate that the internal friction angle of sandstone with joint is very similar to the friction angle of intact sandstone. It can also be stated that fractured rocks still show a small cohesion of joints, amounting to at least several $\mathrm{kPa}$, not only in the case of joints filling with clay or bentonite (Hoek et al., 1995). The joint cohesion exceeding 130$150 \mathrm{kPa}$ is rather typical for igneous rocks, and of $300 \mathrm{kPa}$ for basalts (Wines and Lilly, 2003). 
Similar conclusions were drawn by Kabeya and Legge (1997), claiming that values of internal friction angle and joint surface roughness depended on rock grain size. In order to test this thesis for all sandstone specimens, analysis was performed on the slices specially prepared for this purpose, with the help of polarisation microscope. The microscope analysis served to assess average, minimum and maximum diameters, median, modal value, grain surface area, their slant and flattening. On the basis of the results obtained, a rather strong correlation was determined between maximum grain diameter $d_{\max }$ and the internal friction angle (Fig. 17), for which the determination coefficient $\mathrm{R}^{2}$ amounts to $64 \%$. This is a linear function, which can be presented for sandstones as: $\phi=0.0035 d_{\max }+36.45$, where $d_{\max }$ is expressed in $\mu \mathrm{m}$. However, there is no correlation between grain diameter and cohesion (Fig. 17). At the same time, a slightly weaker correlation can be observed between grain surface area and the JRC factor (Fig. 18), which can also be expressed with a linear function with the determination coefficient $\mathrm{R}^{2}$ amounting to $38 \%$ (except for sample 118).

Table 2 presents the change in joint roughness coefficient for the three consecutive shear tests, namely with an increase in normal stress applied, as described in Section 2. Because together with the shearing process, the proportion of shear and normal stress decreased, it can be therefore observed that the JRC for consecutive shear series increases. In the case of fine-grained sandstones, it adopts values from 3.4 to 6.2 in the first shear, when normal stress $\sigma_{1}$ amounted to approx. $0.25 \mathrm{MPa}$, from 5.3 to 7.1 where $\sigma_{2}$ amounted to approx. $0.50 \mathrm{MPa}$, and from 4.2 to 7.7 at $\sigma_{3}$ of approx. $0.80 \mathrm{MPa}$. In the case of mediumgrained sandstones, it adopts values of from 3.9 to 11.1 at normal stress of approx. $0.25 \mathrm{MPa}$, from 4.4 to 12.5 at $\sigma_{2}$ approx. $0.50 \mathrm{MPa}$, and from 4.8 to 13.6 at $\sigma_{3}$ of approx. $0.80 \mathrm{MPa}$. Generally, JRC values remain within the range of 4-7. According to the description of joint roughness proposed by Barton and Chubey (1977), this is discontinuity profile type 3 or 4. According to the joint roughness guide proposed by Barton and Bandis (1990), these can be defined as undulating slickensided surface.

\section{ASSESSMENT OF JOINT STIFFNESS}

In relation to the change in the value of normal stress applied to the discontinuity in the rock mass, its normal stiffness increases, together with shear stiffness. Its quantitative practical assessment is very difficult, as the actual fracture surface, roughness height and thickness of possible slip surface are never known. In literature, these values significantly differ. UDEC programme (2000) suggests that values forshear stiffness $k_{s}=10-100 \mathrm{MPa} / \mathrm{m}$ in the case of joint filling with clay, while for magmatic rocks $-100 \mathrm{GPa} / \mathrm{m}$, and even up to $250-450 \mathrm{GPa} / \mathrm{m}$. Default values in Phase2 software (2013) amount to $k_{n}=100 \mathrm{GPa} / \mathrm{m}$ and $k_{s}=10 \mathrm{GPa} / \mathrm{m}$, respectively.
In turn, while analysing tests carried out on fractured rocks without filling, such as: granite, marble, Rechitskii (1998) the peak values of shear stiffness $k_{s i}$ obtained equal to $1.8-4.3 \mathrm{GPa} / \mathrm{m}$, and a stiffness within the slip zone of $k_{\text {slim }}=160$ $430 \mathrm{MPa} / \mathrm{m}$. For sandstone and tuffaceous sandstone, the author provides the above values in the ranges of $k_{s i}=1.2-1.3 \mathrm{GPa} / \mathrm{m}$ and $k_{\text {slim }}=200-260 \mathrm{MPa} / \mathrm{m}$, respectively. In the case of joint filling with external material, stiffness decreases, and is the lowest for phyllites and chalk $-k_{s i}=39-43 \mathrm{MPa} / \mathrm{m}$ amd $k_{\text {slim }}=$ 8-12 MPa/m. According to Rechitskii, differences in stiffness can be of up to 50 times the value. He performed tests in the area of shear stresses of up to $1 \mathrm{MPa}$.

In their work on basalt and diabase, Wines \& Lilly (2003) write that the highest (peak) shear stiffness at normal stress values of $0.2 \mathrm{MPa}, 0.5 \mathrm{MPa}$, and $0.9 \mathrm{MPa}$ amount to: for diabase $4.6 \mathrm{MPa} / \mathrm{m}$, $10.3 \mathrm{MPa} / \mathrm{m}$ and $17.4 \mathrm{MPa} / \mathrm{m}$, while for basalt: 4.7 MPa/m, $10.7 \mathrm{MPa} / \mathrm{m}$ and $18.1 \mathrm{MPa} / \mathrm{m}$. Shear stiffness in the slip zone for diabase amounted to $46.1 \mathrm{MPa} / \mathrm{m}, 74.8 \mathrm{MPa} / \mathrm{m}$ and $116.9 \mathrm{MPa} / \mathrm{m}$, thus it was 7-10 times higher. It must also be pointed out that the stress values selected by Wines and Lilly are the ones practically applied to Carbon sandstones by the Author.

In order to find the shear stiffness in sandstones Rechitskii (1998) approach has been employed, assuming that shear stiffness is a quotient of maximum shear stress and corresponding displacement. Analysis of the test results obtained for fine- and medium-grained sandstones show that the average shear stiffness of joints in the slip zone amounted to the following consecutive normal stress ranges was: $320 \mathrm{MPa} / \mathrm{m}, 353 \mathrm{MPa} / \mathrm{m}$ and $418 \mathrm{MPa} / \mathrm{m}$ (Table 3). Generally, test results do not differ from the values presented for sandstones by Rechitskii (1998), and are of the same order of magnitude as the test results obtained by Wines \& Lilly (2003). In turn, sandstones from Kangaroo Valley (Haque, 1999) provided results of approx. $180-200 \mathrm{MPa} / \mathrm{m}$, at a shear displacement rate of $1.20-1.67 \mathrm{~mm} / \mathrm{min}$, thus as applied during the measurements performed by the author.

When analysing interdependencies between shear stiffness and normal stress, one can observe a lack of clear correlation between the values for both analysed sandstone types (Figs. 19 and 20). This again shows a random generation of fracture surface, and the impossibility of a clear prediction of joint stiffness together with the increase of stress applied to it (e.g. related to increased deposition depth). It must be noted, however, that there is a trend of increase in the shear stiffness together with increased normal stress, which for average values is similar to the linear increase (Fig. 21). Due to the small number of test ranges, this cannot be generalised here, but it could explain the high stiffness values adopted during numerical modelling. On the basis of the analysis 
Table 3 Values of shear stiffness $k_{s}$ at sandstone joints for three ranges of normal stress.

\begin{tabular}{|c|c|c|c|c|c|c|c|c|c|c|c|c|c|c|}
\hline \multirow{2}{*}{$\begin{array}{c}\text { Normal } \\
\text { stress } \\
\mathrm{s}[\mathrm{MPa}] \\
\end{array}$} & \multicolumn{14}{|c|}{ Shear stiffness $k_{s}[\mathrm{MPa} / \mathrm{m}]$} \\
\hline & No. 3 & No. 10 & No. 16 & No. 22 & No. 65 & No. 66 & No. 82 & No. 100 & No. 118 & No. 121 & No. 122 & No. 133 & No. 165 & No. 169 \\
\hline $0,19,0,35$ & 240 & 83 & 211 & 89 & 333 & 357 & 255 & 726 & 207 & 236 & 605 & 424 & 559 & 161 \\
\hline $0,38,0,70$ & 310 & 119 & 320 & -- & 226 & 318 & 356 & 537 & 243 & 404 & 639 & 352 & 471 & 290 \\
\hline $0,59,1,08$ & 397 & -- & 332 & 120 & 382 & 278 & 579 & 604 & 240 & 488 & 671 & 426 & 476 & 437 \\
\hline
\end{tabular}

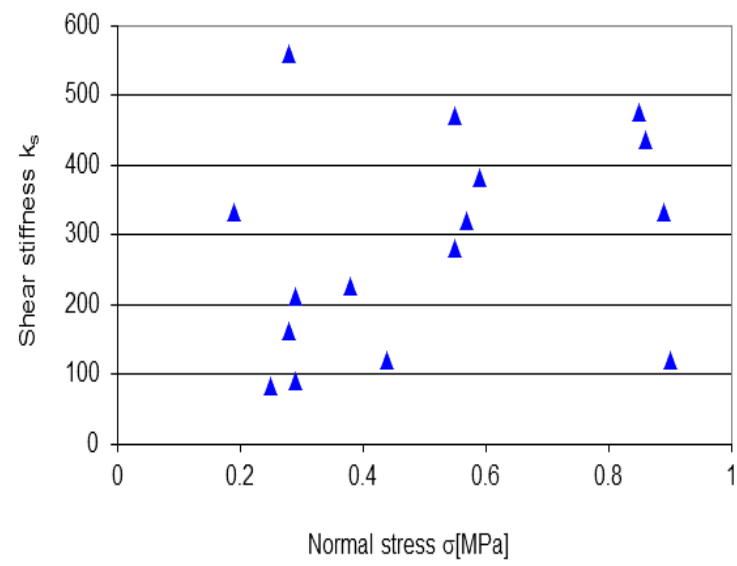

Fig. 19 Correlation between normal stress and shear stiffness for fine-grained sandstone.

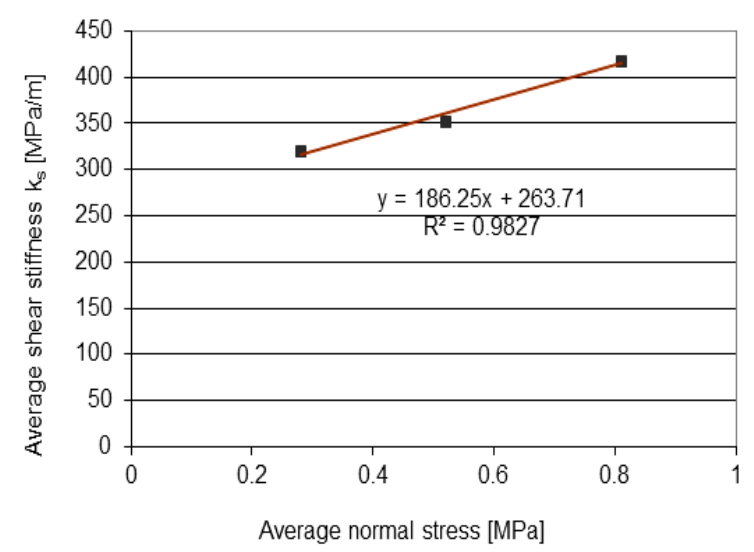

Fig. 21 Average shear stiffness vs. average normal stress for the all three shear tests.

performed, it can be estimated that at a depth of $800 \mathrm{~m}$ at a bulk density of the rock amounting to $25 \mathrm{kN} / \mathrm{m}^{3}$, shear stiffness $k_{s}$ would total $4.0 \mathrm{GPa} / \mathrm{m}$, while at a depth of $1000 \mathrm{~m}$, at bulk density of rock equal to $27 \mathrm{kN} / \mathrm{m}^{3}$, shear stiffness $k_{s}$ would amount to $5.3 \mathrm{GPa} / \mathrm{m}$.

Although the values of normal stress applied during the tests $(0.3 \div 1.0 \mathrm{MPa})$ were much lower than the ones that are actually present in the rock mass at large depths, it must be pointed out that the internal friction angle in Coulomb theory equals to:

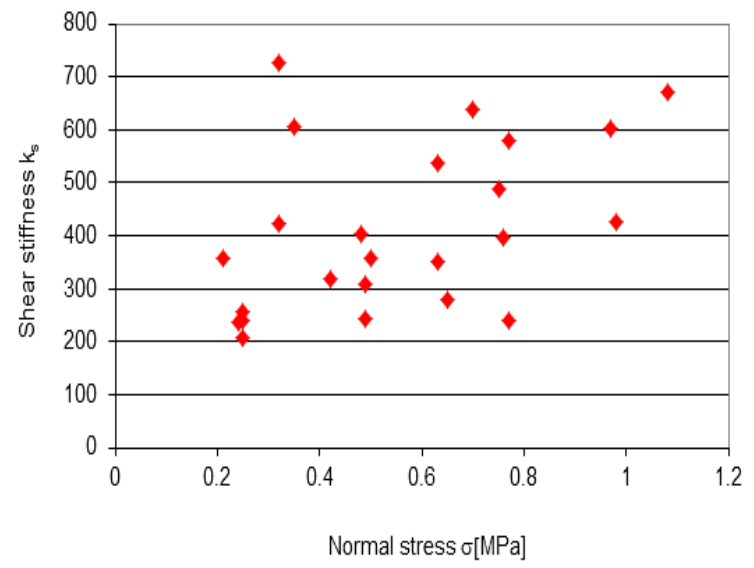

Fig. 20 Correlation between normal stress and shear stiffness for medium-grained sandstone.

$\varphi=\operatorname{arctg}\left(\frac{\tau-c}{\sigma}\right)$,

where: $\sigma$ and $\tau$ are, respectively, normal and shear stresses at joint surface, while $c$ is cohesion. Therefore, even assuming the lack of cohesion of joints $(c=0)$, the proportion of shear and normal stress for the average friction angle $41.45^{\circ}$ obtained would amount to 0.9 . It can thus be considered that in the case of numerical modelling with joint function, the limit proportion of shear and normal stress in the joint must amount to $\operatorname{tg} \phi$, where $\phi$ is the internal friction angle of the joint. The same conclusions were presented by Haque (1999). This indicates that with the assumption of a constant average distance between fractures, normal and shear stiffness of joints should be equal, or shear stiffness should slightly exceed normal stiffness. The situation completely changes in the case of joint filling with another material, in particular those of a clayey nature. In this case, normal stiffness starts to significantly exceed shear stiffness (Hoek et al. 1995).

\section{CONCLUSIONS}

The friction resistance tests carried out for fractured sandstone confirm that joint wall friction occurs with time and a gradual decrease of friction angle, but this is a slow process. Differences in friction resistance result from the amount of normal 
stress applied. This phenomenon inside the rock mass can be caused by additional movements of the rock due to mining operations (Diederichs and Kaiser, 1999).

The friction angle in the fractured fine- and medium-grained sandstones analysed ranges from $33^{\circ}$ to $49^{\circ}$. The rather hard carboniferous sandstone of grainy structure analysed and silicon bond can definitely remain in the medium range of the aforementioned values. Conclusion about the similar friction angle of intact and fractured sandstones can be very useful for geological or engineering designing when evaluate the shear resistance between sandstone rock blocks. The question remains is it possible for grainy rocks to significant reduce the friction on their crack surfaces at high stresses? As in the case of studies by Sanetra (2005), the differences in the values of friction angle at shear surface for fractured and intact sandstones tested at the stress of $10-30 \mathrm{MPa}$ must not be higher than $2-3^{0}$, and the angle itself drops down from $41^{0}$ to $28^{0}$.

It must also be noted that for low values of normal stresses between rock grains, there must also be cohesion, and in many cases the residual angle $\phi_{\mathrm{r}}$ in Coulomb equation (11) can be replaced with an angle of $\phi_{b}(10)$. This does not only have to happen at very high stress levels, however (Barton, 1976). In practice, the first peak for shear resistance related to the occurrence of unsmoothed protrusion at the discontinuity surface must be neglected. At the joint, rock particles interact slightly, which results in a slight yet noticeable cohesion that usually amounts to about over a hundred $\mathrm{kPa}$. It, however, depends strictly on the matrix type.

The studies and analyses performed also indicate that deformability of joints expressed with normal stiffness $k_{n}$ and shear stiffness $k_{s}$ should not differ by as much as 10 times. Analyses suggest that the proportion should remain within the range of 1 to 3.4. Laboratory tests indicate that the proportion between shear and normal stress during the shearing process is close to one, while in the case of a high roughness of joints it can even increase. Based on Coulomb's hypothesis, it can be stated that limit proportion of shear and normal stress in joints amounts to $\operatorname{tg} \phi_{\beta}$. Because rock deformability increases proportionally to their strength, and both stiffness types are related to the fracture system present in the rock, it can be stated that $k_{n} \approx k_{s}$, and in the case of very rough fracture surfaces $k_{n}<k_{s}$ (based on numerical programmes built-in formulas - chapter 2). For fine- and mediumgrained sandstones, average shear stiffness of joints at the slip zone was obtained as follows: $320 \mathrm{MPa} / \mathrm{m}$, $353 \mathrm{MPa} / \mathrm{m}$ and $418 \mathrm{MPa} / \mathrm{m}$, but for the low normal stress.

The study indicates that there is a trend of increase in the shear stiffness together with increased normal stress, which for average values is similar to the linear increase. It can also be stated that the value of internal friction angle depends on the largest diameter of grains occurring on the fracture surface, hence microscopic analysis can be useful for the assessment of shear resistance on the surface of discontinuity.

It is worth noting that according to charts prepared by Barton and Chubey (1977), JRC coefficient for sandstones tested is also typical for intact rock. For the fine-grained sandstone analysed amounts to 5-7, while for medium-grained sandstone: 6-8.

One must also keep the water conditions in mind in the area of the modelled roadway. Water will reduce friction in joints, and the shearing strength parameters obtained during experiments must therefore be reduced by several degrees (Hoek et al., 1995; Goodman, 1989; Brady and Brown; 2004; Hoek, 2013). The stiffness will drop down then too.

\section{REFERENCES}

Arunakumari, G. and Madhavi Latha, G.: 2007, Parametric studies of an underground excavation in jointed rock mass. Numerical Models in Geomechanics - NUMOG $X$, Pande \& Pietruszczak eds., Taylor \& Francis Group, London, 399-404.

Barton, N.R.: 1972, A model study of rock-joint deformation. International Journal of Rock Mechanics \& Mining Sciences, 9, 579-602. DOI: 10.1016/0148-9062(72)90010-1

Barton, N.: 1973, Review of a new shear strength criterion for rock joints. Engineering Geology, 7, 287-32. DOI: 10.1016/0013-7952(73)90013-6

Barton, N.: 1976, The shear strength of rock and rock joints. International Journal of Rock Mechanics \& Mining Sciences and Geomechanical Abstracts, 13, No. 9, 255-279. DOI:.10.1016/0148-9062(76)90003-6

Barton, N.: 1995, The influence of joint properties in modelling jointed rock masses. Keynote lecture, $8^{\text {th }}$ ISRM Congress, Tokyo, 3, Balkema, 1023-1032.

Barton, N. and Bandis, S.C.: 1990, Review of predictive capabilities of JRC-JCS model in engineering practice. Proceedings of International Symposium on Rock Joints, Loen, 603-610.

Barton, N. and Choubey, V.: 1977, The shear strength of rock joints in theory and practice. Rock Mechanics, no. $10,1-54$.

Benmokrane, B. and Ballivy, G.: 1989, Laboratory study of shear behaviour of rock joints under constant normal stiffness conditions. Rock Mechanics as a Guide fro Efficient Utilization of Natural Resources, Khair (ed.), Balkema, Rotterdam.

Brady, B.H.G. and Brown, E.T.: 2004, Rock Mechanics for Underground Mining. Third Edition, Springer, Dordrechts.

Bukowska, M.: 2005, Mechanical properties of carboniferous rocks in the Upper Silesian Coal Basin under uniaxial and triaxial compression tests. Journal of Mining Science, 41, Issue 2, 129-133. DOI: $10.1007 / \mathrm{s} 10913-005-0073-5$

Bukowska, M. and Sanetra, U.: 2008, The tests of the conventional triaxial granite and dolomite compression in the aspect of their mechanical properties. Mineral Resources Management, 24, Issue 2, part 3, 345-358. 
Coulson, J.H.: 1972, Shear strength of flat surfaces in rock. Proceedings of $13^{\text {th }}$ Symposium on Rock Mechanics. American Society of Civil Engineers, New York, 77105.

Diederichs, M.S. and Kaiser, P.K.: 1999, Tensile strength and abutment relaxation as failure control mechanism in underground excavations. International Journal of Rock Mechanics \& Mining Sciences, 36, No. 1, 6996. DOI: $10.1016 / \mathrm{S} 0148-9062(98) 00179-\mathrm{X}$

Flac 7.0 Manuals. Chapter 3 - Interfaces.

Gerrard, C.: 1986, Shear failure constraints for of rock joints: Appropriate empirical relations. International Journal of Rock Mechanics \& Mining Sciences \& Geomechanics, Abstracts, 23, no. 6, 421-429. DOI: 10.1016/0148-9062(86)92307-7

Goodman, R.E.: 1989, Introduction to Rock Mechanics. Second Edition. John Willey and Sons. New York / Chichester / Brisbane / Toronto / Singapore.

Grasselli, C.,: 2001, Shear strength of rock joints based on quantified surface description. These no 2404, Departement de Genie Civil, Ecole Polytechnique Federale de Lausanne

Haque, A.: 1999, Shear behaviour of soft rock joints under constant normal stiffness. Department of Civil. Mining and Environmental Engineering. University of Wollongong. research online.

Hoek, E.: 2013, Shear strength of discontinuities. In Practical Rock Engineering. Hoek's Corner (2007 ed.), 2013-12-17.

Hoek, E., Carranza-Torres, C. and Corkum, B.: 2002, HoekBrown criterion -2002 edition. Proc. NARMS-TAC Conference, Toronto, 1, 267-273.

Hoek, E., Kaiser, P.K. and Bawden, W.F.: 1995, Support of Underground Excavations in Hard Rock. A.A. Balkema, Rotterdam/Brookfield.

Kabeya, K.K. and Legge, T.F.H.: 1997, Relationship between grain size and some surface roughness parameters of rock joints. International Journal of Rock Mechanics \& Mining Sciences, 34, no. 3-4, paper no. 146 .
Krsamanovic, D.: 1967, Initial and residual shear strength of hard rocks. Geotechnique no 15, 145-160.

Małkowski, P.: 2013, The role of damage zone in the coalmine roadways stability assessment. Wydawnictwa AGH, seria: Monografie nr. 265, Kraków, (in Polish).

Phase2 Tutorials. www.rocscience.com. 2013-12-12.

Rechitskii, V.I.: 1998. Evaluation of the stiffness characteristics of rock joints from data field observations at water-development projects. Hydrotechnical Construction, 32, no. 8, 463-469.

Sanetra, U.: 2005. The change of internal friction angle of intact and jointed rock on different depth. Proceedings of Mining Workshops 2005, Polska Akademia Nauk, Wydawnictwo IGSMiE PAN. Kraków. 481-492, (in Polish).

Sridevi, J. and Sitharam, T.G.: 2000, Analysis of strength and moduli of jointed rocks. International Journal of Geotechnical and Geological Engineering, 18, 3-21.

UDEC (Universal Distinct Element Code) Version 3.0. User's Manual. Itasca 2000.

Wines. D.R. and Lilly. P.A.: 2003, Estimates of rock joint shear strength in part of the Fimiston open pit operation in Western Australia. International Journal of Rock Mechanics \& Mining Sciences, 40, 929-937. DOI: $10.1016 / \mathrm{S} 1365-1609(03) 00020-0$

Yamachi, H., Hirai, M., Nakata, M. and Samuraj, S.: 1989, Mechanical behaviour of jointed rock masses supported with rock bolts. Rock at Great Depth, Maury \& Fourmaintraux eds., Balkema Rotterdam, 497-504. 